Arkivoc

Free to Authors and Readers
A Platinum Open Access Journal for Organic Chemistry

Paper

DOAJ Seal
Arkivoc 2021, part iv, 268-279

\title{
Thio-glycomimetics with enhanced lipophilicity and their biological activity
}

\author{
Zbigniew J. Witczak, ${ }^{* a}$ Anastasia Mauger, ${ }^{a}$ Roman Bielski, ${ }^{a}$ and Donald E. Mencerb \\ ${ }^{a}$ Department of Pharmaceutical Sciences, ${ }^{b}$ Department of Chemistry and Biochemistry, Wilkes University, \\ 84W South Street, Wilkes-Barre, PA 18766, USA \\ Email: zbigniew.witczak@wilkes.edu
}

This paper is dedicated to Professor Horst Kunz on the occasion of his $80^{\text {th }}$ birthday

Received 10-11-2020

Accepted 02-14-2021

Published on line $02-18-2021$

\section{Abstract}

The thio-linked glycomimetics were prepared via a base-catalyzed, highly stereo-selective Michael condensation of levoglucosenone with various sugar, heterocyclic and adamantane thiols in order to generate a library of analogs with comparative level of lipophilicity for further biological screening as antibacterial and anticancer agents. The comparative analysis of earlier synthesized library of previously synthesized glycomimetics with the new analogs exhibiting more lipophilic character is also presented. ${ }^{1} \mathrm{H} N M R,{ }^{13} \mathrm{C} \mathrm{NMR}$, and single-crystal x-ray diffraction of the unexpected addition and cyclization product unequivocally confirm the structural assignments. Mechanistic insights related to the synthesis of new products are also proposed and discussed.
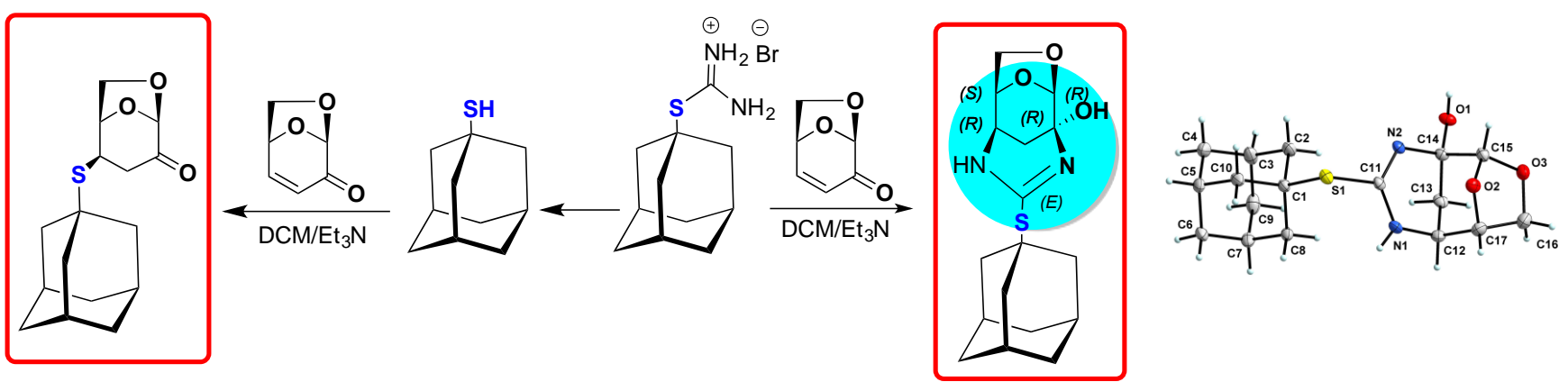

Keywords: Adamantanes, levoglucosenone, 1,4-S-thiodisaccharides, 2-thiazoline, 1,3,4-thiadiazole. 


\section{Introduction}

$S$-thio-linked glycomimetics ${ }^{1}$ are one of the most explored areas of modern synthetic carbohydrate chemistry. Among them, thiodisaccharides ${ }^{2,3}$ are examples of non-hydrolyzable glycomimetics containing the sulfur atom in the glycosidic linkage. Such compounds have been synthesized previously by a variety of methods ${ }^{4,5}$ including $S_{N}$-type reactions involving the action of a thiolate anion and a glycosyl halide. The alternative methodology is a thio-Michael addition to conjugated systems such as carbohydrate enones ${ }^{6}$. Reactive thiols are always used as strong nucleophilic agents. The greater acidity of thiols as compared to alcohols, despite the fact that sulfur is less electronegative than oxygen, can be traced to the lower S-H bond energy and overall reactivity of thiols. Some selectivity in thiol-Michael reactions were reported in the recent literature. ${ }^{7,8}$ These developments are extremely important for the application of the catalyst/initiator-driven selectivity in synthetic carbohydrate chemistry. ${ }^{9}$

The hydrophilic-lipophilic balance (HLB) effect is an important factor to consider when designing novel therapeutic agents, including thiodisaccharides, since pharmacokinetic properties have been utilized to improve existing drugs including thio-sugars.

Functionalization of carbohydrates by the adamantane moiety has been reported in the literature ${ }^{10-13}$. Adamantane as a "lipophilic bullet" ${ }^{14}$ is a perfect tool for the enhancement of lipophilicity of pharmaceuticals and existing commercial drugs. ${ }^{14}$ Adamantane modifications were chosen in this study to enhance lipophilicity and stability of the potential drugs, thereby improving their pharmacokinetics. We are presenting here some preliminary data on the correlation of lipophilicity and biological responses of some of the selected glycomimetics derivatives, such as $2,3,4,5,9,10,11,12$ and 13 .

\section{Results and Discussion}

Our earlier data on base-catalyzed conjugate Michael reaction addition of reactive carbohydrate 1-thiols to the conjugated system of levoglucosenone (LG), revealed that the addition reaction is completely stereoselective and gives a high yield of 1,4-addition products. ${ }^{4-5}$ The 1,6 anhydro bridge of levoglucosenone enforces a rigid conformation of the system and sterically hinders the $\beta$-face of the molecule, so the nucleophilic additions of reactive thiols generally occurs at the C-4 position in kinetically controlled reactions with an exclusive attack at the exo-face of levoglucosenone. Concurrently, the 1,6-anhydro bridge sterically hinders the endo-face of the molecule. The stereochemistry of the 4-S-link in compound $\mathbf{2}$ was determined by ${ }^{1} \mathrm{H}$ NMR spectral analysis and by X-ray crystallography as depicted in scheme 1.

The biological activity of fully protected per-acetylated thiodisaccharide $\mathbf{2}$ revealed that minimum inhibitory concentration $\left(\mathrm{MIC}_{50}\right)$ for inhibition of Mycobacterium tuberculosis was observed at $0.05 \mathrm{mM}$ level. ${ }^{15}$ That important information on selective bactericidal inhibitory activity prompted us $^{16}$ to investigate the uptake mechanism of thiodisaccharide $\mathbf{2}$ identifying the role of PPE51 proteins (Pro-Pro-Glu (PPE) motif in their 110 and 180 amino acid $\mathrm{N}$-terminal regions), which participates in the uptake process of thiodisaccharide 2 into Mycobacterium tuberculosis. This is a cornerstone discovery that provided evidence for a specific mechanism of action of inhibition of Mycobacterium tuberculosis by thiodisaccharides for the first time. Additionally, inhibitory activity of Escherichia coli was observed at minimum inhibitory concentration $\left(\mathrm{MIC}_{50}\right)>$ $5 \mathrm{mM}$ and inhibition of Staphylococcus aureus was observed at $\mathrm{MIC}_{50}>2.5 \mathrm{mM}$ as well. 
Surprisingly, the galacto analog $\mathbf{3}$ was totally inactive when screened for inhibitory activity of Mycobacterium tuberculosis, Escherichia coli and Staphylococcus aureus respectively. Deprotection, (deacetylation) of both thiodisaccharides $\mathbf{2}$ and $\mathbf{3}$ produced water-soluble analogs, 2A and 3A, which turned out to be completely inactive against screened bacteria. We, therefore, speculate that presence of acetyl group at the C-4 position may play some role in response with against those pathogens. We can also speculate that despite the identical level of (-) lipophilicity, at some point the polarity of the deprotected molecules $\mathbf{2 A}$ and $\mathbf{3 A}$ is at the high end with significantly reduced lipophilicity to the level of not effective penetration through lipid bilayers of the bacterial cells.

This surprising observation, when correlated with calculated value of LogP of -2.05 for both gluco $2 \mathrm{~A}$ and galacto $3 \mathbf{A}$ analogs prompted us to modify the aglycone moiety of the remaining core structure of the protected sugar moiety.

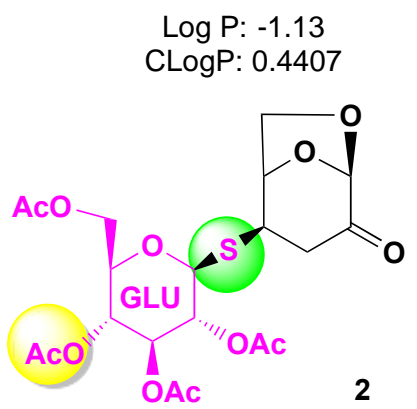

$\mathrm{MIC}_{50}=0.05 \mathrm{mM} /$ CFUAnti-Mtb $\mathrm{MIC}_{50}=5 \mathrm{mM} / \mathrm{E}$. coli $\mathrm{MIC}_{50}=2.5 \mathrm{mM} / \mathrm{S}$. aureus

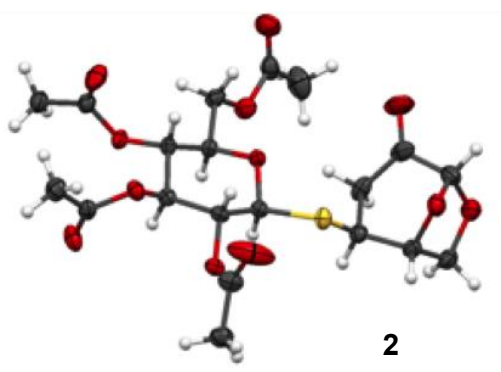

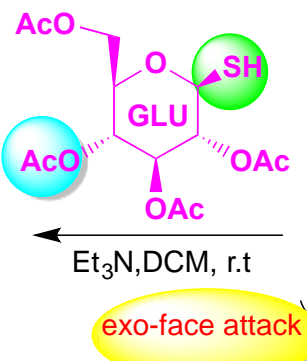

Log P: -2.05

CLogP: -1.69975

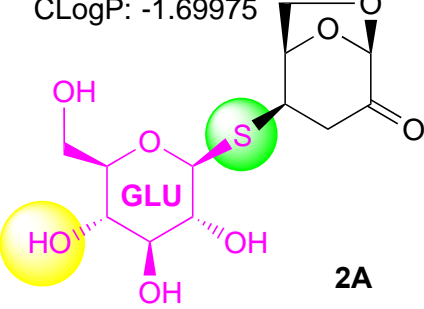

Gluco INACTIVE

1
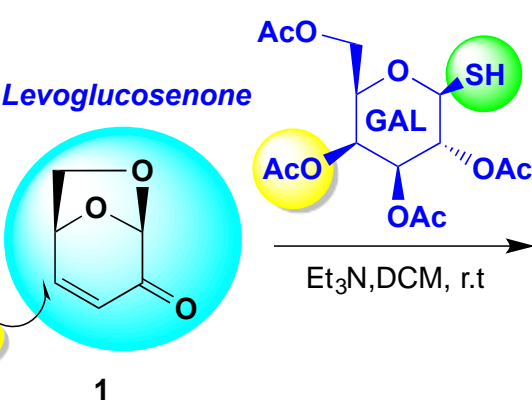

Log P: -2.05

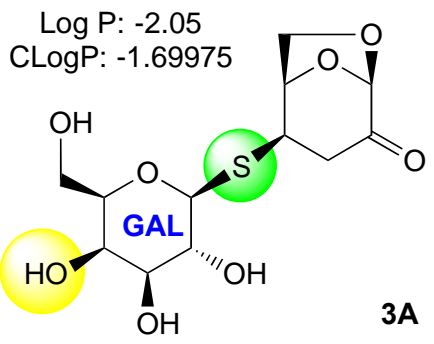

Galacto INACTIVE

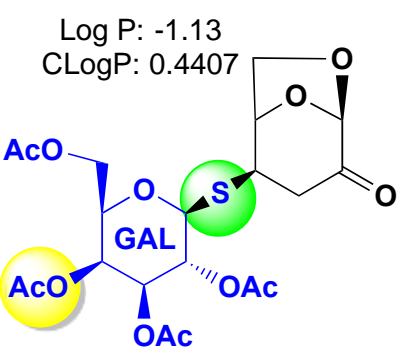

3 Galacto INACTIVE

Scheme 1. Biological activity of 1,4-S-thiodisaccharides 2, 3 and 2A, 3A.

When we expanded the Michael conjugate addition approach of selected heterocyclic thiols such as 2thiol-5-aminothiadiazole and 2-thiol-thiazoline to levoglucosenone ${ }^{15}$ we found that the reaction proceeds with complete stereo-selectivity, as only one isomer of 4-thio- derivatives $\mathbf{4}$ and $\mathbf{5}$ was produced and in high yield $(>85 \%)$ as depicted in Scheme 2 . The biological screening revealed that 4-S-thiadiazole 4 , was inhibiting Mycobacterium tuberculosis at $0.025 \mathrm{mM}$ level. Additionally, inhibitory activity of Escherichia coli was observed at minimum inhibitory concentration (MIC) $>1.25 \mathrm{mM}$ and inhibition of Staphylococcus aureus was observed at $\mathrm{MIC}_{50}>0.625 \mathrm{mM}$ respectively. Interestingly, thiazoline $\mathbf{5}$ exhibited a weaker inhibitory activity on both Escherichia coli and Staphylococcus aureus at $2.5 \mathrm{mM}$ level respectively. It is worth noting that despite similar levels of lipophilicity ( $\log P$ ) for both compounds $\mathbf{4}$ and $\mathbf{5}$, the thiazoline $\mathbf{5}$ responded with weaker inhibitory activity against Mycobacterium tuberculosis at $0.05 \mathrm{mM}$ level. That observation strongly suggests that the 
primary amino functional group at C-5 of 1,3,4-thiadiazole moiety of compound 4 is involved in critically important and stronger inhibitory response when compared to thiazoline 5.
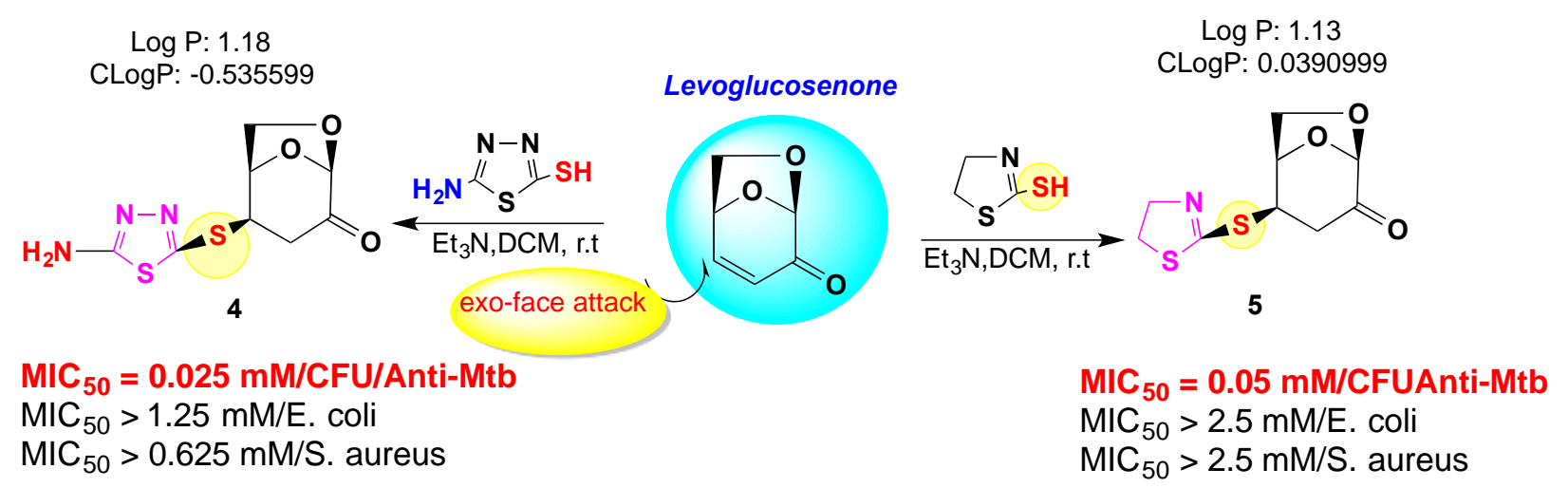

Scheme 2. Biological activity of 4-S-thiofunctionalized levoglucosenone derivatives $\mathbf{4}$ and $\mathbf{5}$.

Similar inhibitory activity of Mycobacterium tuberculosis at $\mathrm{MIC}_{50}=0.05 \mathrm{mM}$ level was observed for thiazoline adduct 5. Additionally, inhibitory activity of Escherichia Coli was observed at minimum inhibitory concentration $\left(\mathrm{MIC}_{50}\right)>2.5 \mathrm{mM}$ and inhibition of Staphylococcus aureus was observed at $\mathrm{MIC}_{50}>2.5 \mathrm{mM}$ as well. It is also important to notice that the LogP of both compounds 4 and $\mathbf{5}$, are 1.18 and 1.13 respectively. It is well known that if LogP is closer to 2.2-2.5, then the cell lipids membrane penetration is more effective.

These biological inhibitory data and their correlation with the value of Log $\mathrm{P}$, prompted us to design new functionalized thio-linked glycomimetics (as depicted in Figure 1) for study on the antibacterial effects. Substitution of the sugar moiety with heterocyclic moieties of aminothiadiazole, thiazoline and adamantane increases level of lipophilicity. Employing this strategy permits an examination of the relationship between lipophilicity and the level of biological response.

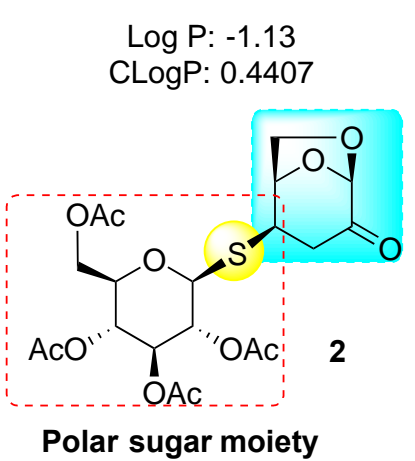

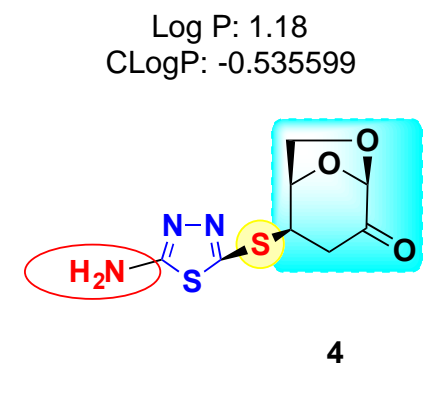

Polar aminothiadiazole moiety
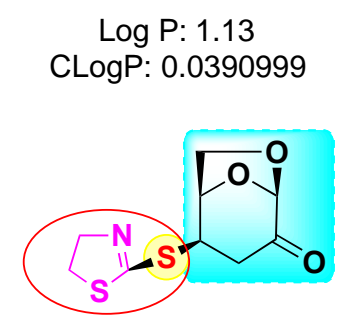

5

Polar thiazoline moiety
Log P: 1.88

CLogP: 2.9607

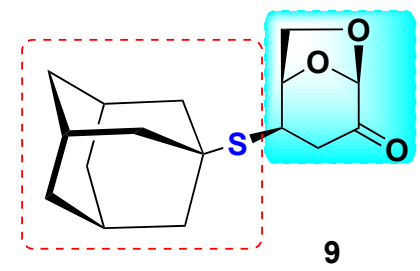

Lipophilic adamantane moiety

Figure 1. Studied LG derivatives thio-coupled to acetylated sugar, heterocycles and adamantane moieties with increased level of lipophilicity.

The adamantane moiety, as a bulky functional group, substantially enhances overall lipophilicity of the target molecule. It is well known as a "lipophilic bullet"14 and it is a core fragment of a few commercial antiviral drugs such as Rimantadine and Amantadine.

Adamantane thioglycosides ${ }^{10-13}$ are known for their biological activity and were synthesized directly from commercially available adamantane 1-thiol $\mathbf{8}^{11,17}$. When we used adamantane-1-thiol 8 as a reactant in the 
base catalyzed Michael addition to levoglucosenone (LG), the stereo-selectivity of the addition was quite predictable and we were able to isolate the 1,4-thio-adduct 9 as a crystalline derivative in a good (74\%) yield. The structure and stereochemistry of the addition reaction product 9 was confirmed by the ${ }^{1} \mathrm{H}$ and ${ }^{13} \mathrm{C} \mathrm{NMR}$ spectral analysis, showing that the hydrogen atom at the position $\mathrm{C}-4$ is axial.

The coupling constants $J_{3 e q, 4}=8.1 \mathrm{~Hz}$ and $J_{3 a x, 4}=1.5 \mathrm{~Hz}$, are informative and unequivocally proved that the adduct 9 must be derived from the exo-face attack of thiol 8.

In an effort to simplify and shorten the thiol preparation approach we used "masked thiols" instead as of the reactive thiol $\mathbf{8}$ in the thio Michael addition reaction to the conjugated system of levoglucosenone (LG) (as shown in Scheme 4).

Ibatulin and coworkers ${ }^{18-20}$ had described the utilization of S-glycosyl isothiourea derivatives as "masked thiols" for the synthesis of thiodisaccharides ${ }^{18}$ and thiooligosaccharides ${ }^{20}$. We followed the reported methodology of Ibatulin ${ }^{18}$ and we adopted his methodology for the base catalyzed Michael addition to levoglucosenone (LG). To our surprise, the S-isothiouronium adamantane 7, when reacted with levoglucosenone $\mathbf{1}(\mathrm{LG})$ in the presence of a base formed an unexpected product 10. Its formation is a result of 1,4 Michael addition to a conjugate system followed by an amino group attack on the keto function at C-2 position. Compound $\mathbf{1 0}$ was the only product isolated from this reaction in a good (72\%) yield. Interestingly, the calculated values of LogP and ClogP for compound 9 (Log P: 1.88 CLogP: 2.9607) are significantly different from the corresponding values for compound 10 (Log P: 2.86, CLogP: 0.82982). This difference may be a reason for different levels of biological response from both compounds 9 and 10.

Log P: 1.88

CLogP: 2.9607

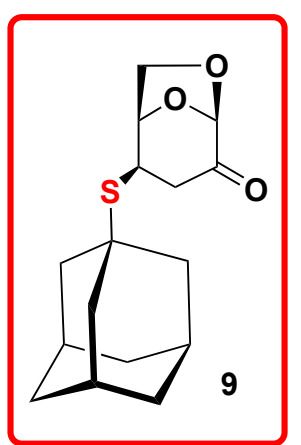

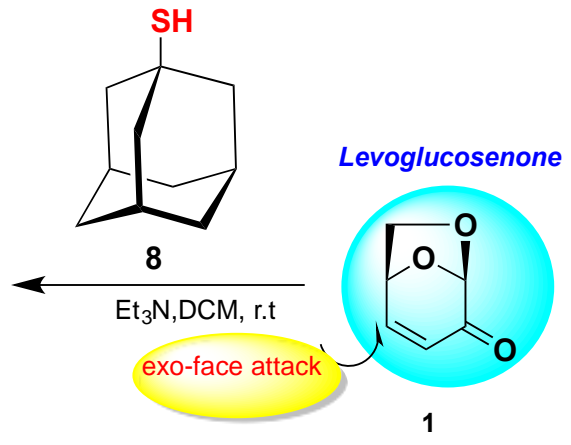

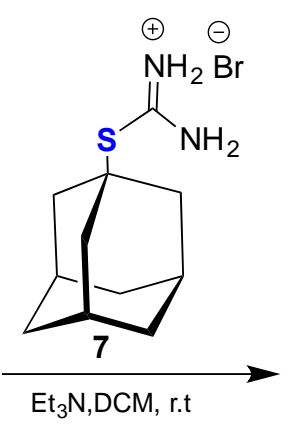

Log P: 2.86 CLogP: 0.82982

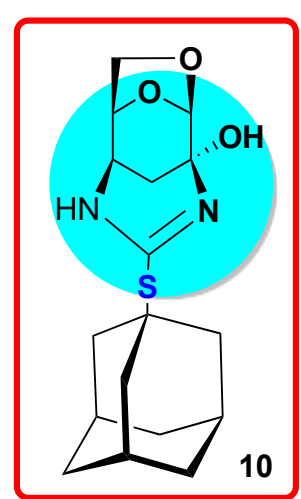

Scheme 3. Michael addition reaction of thiol $\mathbf{8}$ and its "masked thiol" $\mathbf{7}$ to conjugate system of $\mathbf{1 .}$

The first step of a mechanism we consider plausible is the addition of thiouronium moiety to the C-4 position of levoglucosenone (LG) to form a kinetically favored C-N bond. The next step is a further cyclization reaction of activated amino functionality with keto function at C-2 of levoglucosenone as depicted in Scheme 4. 


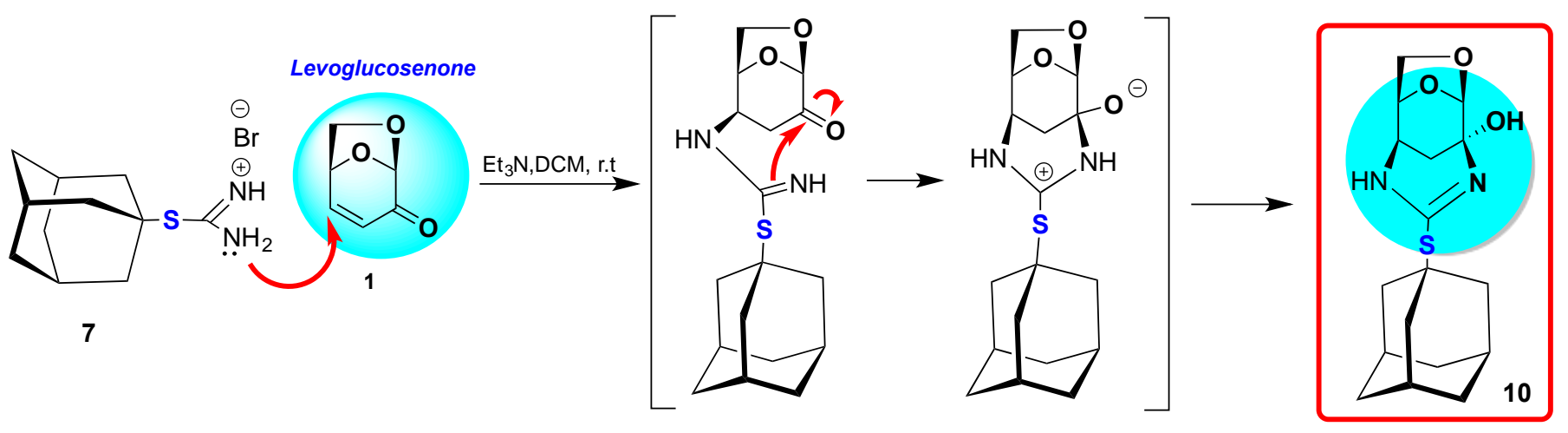

Scheme 4. Plausible reaction mechanism of conjugate addition of thiouronium via Michael addition of thiouronium "masked thiol" 7 to the conjugate system of 1.

Interestingly, triethylamine is a good activator for the conjugate addition of the thiouronium anion to C-4 of levoglucosenone (LG), but unfortunately it is not capable of generating a free thiol from its "masked thiol" derivative 7. A two steps process of an addition followed by cyclization, fits nicely with a definition of a wellknown domino reaction ${ }^{21}$. It is worth noting that this is the first observation of a case in which a "masked thiol" has not generated the expected thiol to react with conjugated system of levoglucosenone (LG) during the base catalyzed Michael addition reaction.

The ${ }^{1} \mathrm{H}$ and ${ }^{13} \mathrm{C}$ (1-D and 2-D) NMR data (see supporting information) of compound 10 confirmed the structural assignment and additionally helped to inform our plausible mechanism of not yet observed "domino reaction" explained below. Additionally, X-ray crystal diffraction analysis (see supporting information) unequivocally identified the structure of the adduct 10, as depicted in Figure 2. Moreover, compound $\mathbf{1 0}$ contains a rare and interesting structural feature: a carbon atom bonded to a hydroxyl group and an imino functionality. This structural feature is also supported by the 1D and 2D NMR data.

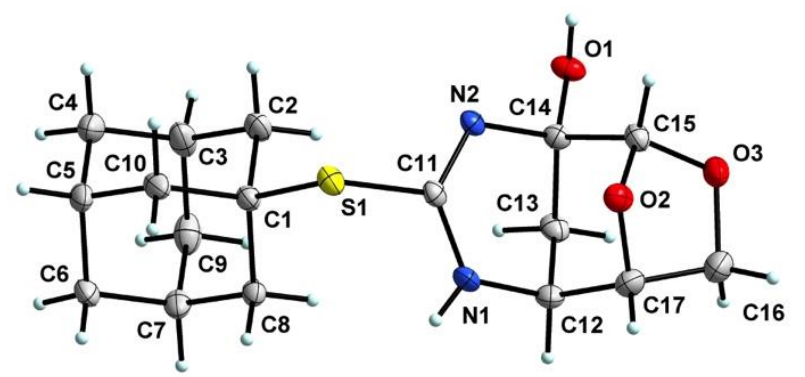

Figure 2. ORTEP diagram of compound 10.

The preliminary data of biological screenings against selected pathogens Escherichia coli and Staphylococcus aureus revealed that both compounds $\mathbf{9}$ and $\mathbf{1 0}$ are practically inactive in inhibiting bacterial cell proliferation at the standard level of $\mathrm{MIC}_{50}>2.5 \mathrm{mM}$. This is quite unexpected and surprising development 
in the light of their different levels of lipophilicity. Additional enhanced screening tests against other bacterial pathogens are under intense investigation in our laboratory to examine this finding further.

Our earlier data on biological in vitro geno- and cyto-toxicity on human ovarian carcinoma (A2780) and cisplatin resistant ovarian carcinoma cell line (A2780CIS) of new thio-adamantane derivatives 11, 12 and 13 as depicted in Scheme 6, clearly indicates that functionalized carbohydrate adamantane thio-analog 13 was most cytotoxic, which decreased ovarian cell viability at micro-molar $(\mu \mathrm{M})$ concentration ${ }^{22}$. Interestingly, compound 13 exhibits strong bactericidal effect on Mycobacterium tuberculosis at $0.5 \mathrm{mM}$ level ${ }^{15}$.

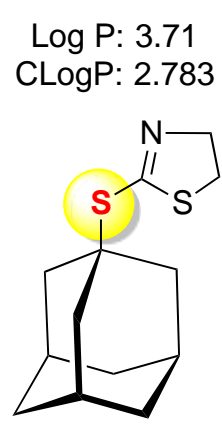

11

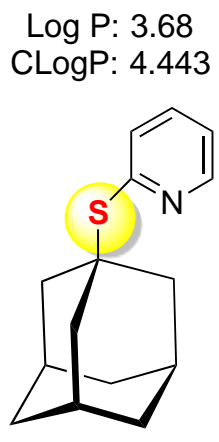

12

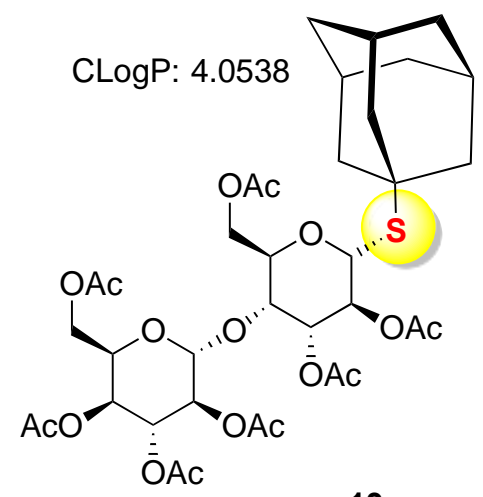

13

Scheme 5. Adamantane thio-linked heterocycles 11, 12 and peracetylated lactose thio-linked derivative 13.

2-Thiopyridine adamantane 12 caused a 53\% decrease in a cis-platin resistant ovarian cancer cell viability and 21\% in A2780 cells at $1 \mathrm{mM}$, whereas 2-thiazoline 11 did not exhibit cytotoxic activity on either cancer cells ${ }^{22}$.

The comparable levels of lipophilicity for all of three functionalized derivatives, highest for both 12 and $\mathbf{1 3}$, additionally suggesting that 2-thiazoline 11 with $\operatorname{LogP}=3.71 \operatorname{Cog} P=2.783$ is not cytotoxic due to insufficient lipophilicity and consequently is not effective in penetration of the membrane of the cancer cells.

These data provide additional support of our latest biological tests on compounds of 9 and 10 and correlation of their lipophilicity levels. The compilation of the antibacterial and cytostatic activity is listed in Table 1. 
Table 1. Antibacterial and cytostatic activity and comparative lipophilicity level

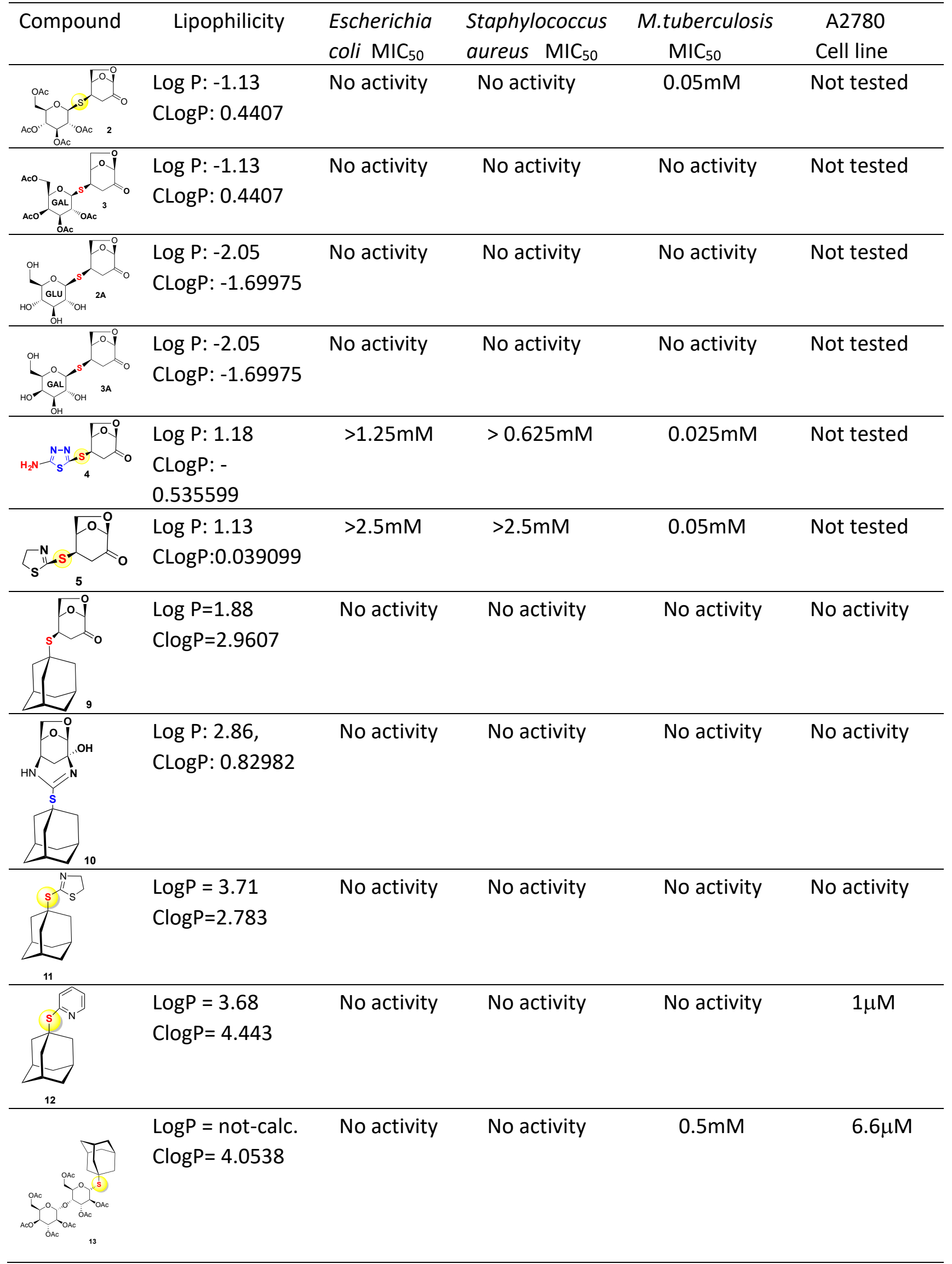




\section{Conclusions}

The presented data show that lipophilicity levels of studied compounds (saccharides coupled via a sulfur atom to another sugar, heterocyclic unit and adamantane) have a profound effect on their biological activity. Specifically, it was demonstrated by measuring the antibacterial effect on Escherichia coli and Staphylococcus aureus and strong bactericidal effect on Mycobacterium tuberculosis, that compounds $\mathbf{4}$ and $\mathbf{5}$ (LG coupled to heterocycles) exhibit the inhibitory effect comparable to that exhibited by $\mathbf{2}$ and $\mathbf{3}$ (LG coupled to acetylated monosugars). In contrast, more lipophilic compounds 9 and 10 (LG coupled to adamantane) lack any antibacterial activity. Additionally, we studied thioadamantane-based compounds $\mathbf{1 1}, \mathbf{1 2}$ and $\mathbf{1 3}$ with enhanced lipophilicity against human ovarian carcinoma (A2780) and cis-platin resistant ovarian carcinoma cell line (A2780CISt). These compounds exhibit substantial in vitro geno-and cytotoxicity at micro-molar level. The further correlation studies are underway and those results will be published separately.

\section{Experimental Section}

General. All reagents and solvents were used as purchased without further purification. ${ }^{1} \mathrm{H}$ NMR and ${ }^{13} \mathrm{C}$ NMR spectra were recorded on a Bruker Avance III 400 Ultrashield Plus spectrometer to assign chemical shift and to determine $\mathrm{C}-\mathrm{H}$ coupling constants. 2D (COSY and HSOC) experiments were performed to enhance assignments. Chemical shifts are reported in ppm with TMS (0 ppm) as an internal standard for ${ }^{1} \mathrm{H}$ NMR and the residual solvent signals $\left(\mathrm{CDCl}_{3}: 7.26 \mathrm{ppm}\right.$, acetone- $d_{6}: 2.05 \mathrm{ppm}$, DMSO- $d_{6}: 2.50 \mathrm{ppm}$ ) for ${ }^{1} \mathrm{H}$ NMR and $\left(\mathrm{CDCl}_{3}: 77.16 \mathrm{ppm}\right.$, acetone- $d_{6}: 206.26 \mathrm{ppm}, 29.84 \mathrm{ppm}$, DMSO- $\left.d_{6}: 39.52 \mathrm{ppm}\right)$ for ${ }^{13} \mathrm{C}$ NMR. Thin layer chromatography was performed on silica gel coated TLC plates and visualized under UV light (at $254 \mathrm{~nm}$ ) or by exposing to iodine $\left(\mathrm{I}_{2}\right)$ vapor. The melting points $(\mathrm{mp})$ were obtained on a Techne Stuart digital melting point apparatus. Optical rotation was measured using a JASCO P-2000 Digital Polarimeter. Chemical names and logP, ClogP values were generated by ChemDraw Professional V.15.1.0.144 software.

2-(Adamantan-1-yl)-isothiouronium bromide (7). Compound 7 was prepared by the original methodology of Bauer ${ }^{17}, \mathrm{R}_{f}=0.59$ (EtOAC), mp. $231-232^{\circ} \mathrm{C}$, lit. ${ }^{17} 231-232^{\circ} \mathrm{C}$, for ${ }^{1} \mathrm{H}$ NMR and ${ }^{13} \mathrm{C}$ NMR data see Ref. ${ }^{17}$

Adamantane-1-thiol (8). Compound 8 was prepared by the methodology of Bauer ${ }^{17}, \mathrm{R}_{f}=0.59$ (EtOAC), $\mathrm{mp}$ 102-103 ${ }^{\circ} \mathrm{C}$, lit. ${ }^{17} 102-104^{\circ} \mathrm{C}$, for ${ }^{1} \mathrm{H}$ NMR and ${ }^{13} \mathrm{C}$ NMR data see Ref. ${ }^{17} .{ }^{1} \mathrm{H}$ NMR $\left(400 \mathrm{MHz}, \mathrm{CDCl}_{3}\right) \delta: 2.09(\mathrm{~s}, 3 \mathrm{H})$, $1.96(\mathrm{~s}, 6 \mathrm{H}), 1.62(\mathrm{~s}, 9 \mathrm{H}) .{ }^{13} \mathrm{C}$ NMR $(125 \mathrm{MHz}, \mathrm{CDCl} 3) \delta: 47.8,43.5,35.6,30.6$.

2-Adamantan-1-yl-thio-6,8-dioxabicyclo[3.2.1] Joctan-4-one (9). To a solution of levoglucosenone 1 (0.73g, 0.2 $\mathrm{mmol})$ in dichloromethane $(10 \mathrm{~mL})$ a solution of 1-thio-adamantane $8(0.84 \mathrm{~g}, 0.2 \mathrm{mmol})$ in $5 \mathrm{~mL}$ of dichloromethane and $0.5 \mathrm{~mL}$ of triethylamine was added dropwise. The reaction mixture was stirred at room temperature for $24 \mathrm{~h}$. After evaporation of the solvent, the syrupy residue was purified by, crystallization from methanol. Yield $(1.08 \mathrm{~g}, 74 \%)$, colorless crystals, m.p.120-121 ${ }^{\circ} \mathrm{C}, \mathrm{R}_{f}=0.39$ (1:4, hexane-EtOAc); $[\alpha]_{D}-128.2$ (c 0.84, $\mathrm{CHCl}_{3}$ ); ${ }^{1} \mathrm{H}$ NMR (400 MHz, $\mathrm{CDCl}_{3}$ ) 8: 3.96- 4.07 (m, 2H, H-6endo and H-6exo), $3.58(\mathrm{~m}, 1 \mathrm{H}, \mathrm{H}-4), 3.09$ ( dd, $\left.1 \mathrm{H}, J_{3 e q, 4} 8.1 \mathrm{~Hz}, J_{\text {gem }} 17.8 \mathrm{~Hz}, \mathrm{H}-3 \mathrm{eq}\right), 2.05$ (dd, $\left.1 \mathrm{H}, J_{3 a x, 4} 1.5 \mathrm{~Hz}, \mathrm{H}-3 \mathrm{ax}\right), 2.09(\mathrm{~s}, 3 \mathrm{H}), 1.96(\mathrm{~s}, 6 \mathrm{H}), 1.69(\mathrm{~s}, 9 \mathrm{H}) .{ }^{13} \mathrm{C}$ NMR (100 MHz, CDCl $): \delta$ 30.7, 32.2 (C-4, C-S), 43.1, 38.7 (C-3), 47.8, 72.4 (C-6), 91.9 (C-5), 127.2 (C-1), 202.0 (C-2, C=O).

8-[Adamantan-1-yl-thio]-9-methyl-3,11-dioxa-7,9 $\lambda^{4}$-diazatricyclo[4.3.1.1 $\left.{ }^{2,5}\right]$ undec-8-en-1-ol $\quad$ (10). To a solution of levoglucosenone $1(0.73 \mathrm{~g}, 0.2 \mathrm{mmol})$ in dichloromethane $(20 \mathrm{~mL})$ a solution of 2-(adamantan-1-yl)isothiouronium bromide $7(1.45 \mathrm{~g}, 0.2 \mathrm{mmol})$ in $5 \mathrm{~mL}$ of dichloromethane was added, followed by the dropwise 
addition of $0.5 \mathrm{~mL}$ triethylamine. The reaction mixture was stirred at room temperature for $48 \mathrm{~h}$. After evaporation of the solvent, the syrupy residue was crystallized from methanol. Yield $(1.2 \mathrm{~g}, 72 \%)$, white crystals, m.p. $164-166^{\circ} \mathrm{C}, \mathrm{R}_{\mathrm{f}}=0.13$ (1:4, hexane-EtOAc); $[\alpha] \mathrm{D}=-134.2$ (c $\left.0.84, \mathrm{CHCl}_{3}\right) ;{ }^{1} \mathrm{H} \mathrm{NMR}(400 \mathrm{MHz}$, $\left.\mathrm{CDCl}_{3}\right): \delta$ 1.51-1.55 (dd), $1.73(\mathrm{~s}), 2.35-2.39$ (dd), 3.55-3.57(q), 3.81-3.84 (dd), 4.13-4.15 (d), 4.46-4.48 (t), 4.99 (s), 13C NMR (100 MHz, CDCl3): $\delta 27.86,30.32,35.87,43.72,49.72,51.92,68.73,79.50,79.52,83.72,105.70$, C-1), 155.07 (= CS), for full spectra 1H NMR, 2D (COSY and HSQC) and 13C NMR and X-crystal structure23 (see supporting information).

\section{In vitro cytotoxicity assay}

The cytotoxicity of the tested compounds was examined in vitro against mouse 1929 fibroblasts. Briefly, the cells were seeded at 103 cells per well in 96-well tissue culture plates and allowed to proliferate at $37 \circ \mathrm{C}$ for 12 h. Confluent monolayers of fibroblasts were treated with different concentrations of the compounds up to $1000 \mu \mathrm{M}$ in triplicate or replaced with fresh medium (untreated controls). The compounds were dissolved in dimethyl sulfoxide (DMSO) or water to form drug solutions and then were suspended in RPMI supplemented with $5 \%$ of FBS, $1 \% \beta$-mercaptoethanol and antibiotics. The final concentration of DMSO in the medium was $0.1 \%$. After a $16 \mathrm{~h}$ or $72 \mathrm{~h}$ incubation at $37{ }^{\circ} \mathrm{C}$ in $5 \% \mathrm{CO} 2$, the number of viable cells was determined by the Cell Counting Kit 8 (CCK-8, Dojindo, Sigma, Munich, Germany). The 50\% cytotoxic concentration (CC50) was defined as the concentration required to reduce the cell growth by $50 \%$ compared to the untreated controls and was calculated with BioDataFit 1.02 software (Chang Bioscience, Fremont, CA, USA).

\section{Bacterial growth conditions and susceptibility tests}

The Mycobacterium tuberculosis H37Rv strain (Mtb) used in this study was cultured in Middlebrook 7H9 broth supplemented with $10 \%$ OADC (oleic acid-albumin-dextrose-catalase)) and $0.05 \%$ Tween-80 (pH 7) and given chemicals at various concentrations when required. The M. tuberculosis H37Rv strain was grown for 4-6 days until the optical density (OD600) reached 1 . Then, the bacterial culture was suspended in fresh medium at an OD600 of approximately 0.1 . The cultures were supplemented with the carbohydrates derivatives and grown for $96 \mathrm{~h}$ at $37{ }^{\circ} \mathrm{C}$. The growth was monitored by OD600 and CFU analyses. The optical density (OD600) was monitored every $24 \mathrm{~h}$ for the control and carbohydrate-supplemented cultures. The number of viable bacilli was determined by the plating of $100 \mu \mathrm{L}$ of appropriate dilutions on Middlebrook 7H10 plates and was followed by the calculation of CFU. The Escherichia coli and Staphylococcus aureus strains were cultured in Mueller-Hinton medium. The susceptibility of $E$. coli and $S$. aureus to the tested carbohydrates was determined by the microdilution method according to standard CLSI techniques. ${ }^{24}$ The analysis was performed in 96-well microplates containing Mueller-Hinton broth. All of the tested compounds were dissolved in water or dimethyl sulfoxide (DMSO). The concentrations of the carbohydrates in Mueller-Hinton broth initially ranged from 10 to $0.078 \mathrm{mM}$. The DMSO control was included in each experiment. The inoculum density was adjusted to a $0.5 \mathrm{McF}$ arland standard. The microplates were incubated at $37 \circ \mathrm{C}$ for $18 \mathrm{~h}$, and the OD600 measurements were determined for the bacterial cultures in the presence and absence of the tested compounds. The MIC analyses were repeated at least three times.

\section{Cell cycle analysis of $\mathrm{A} 2780$ cell line}

A2780 cells were seeded and cultured in the plates for $24 \mathrm{~h}$ before the treatment. Next $I C_{20}$ and $I C_{50}$ concentrations of compounds 12 and 16 were added to the cells. $10 \mu \mathrm{M}$ of nocodazole was used as a positive control of G2/M arrest. After 24 h exposure of A2780 cells with FCPs cancer cells were detached, collected and washed with PBS twice, and then re-suspended in PBS to a final concentration $1 \times 10^{6}$ cells per ml. Next cells 
were incubated for $15 \mathrm{~min}$ on $4{ }^{\circ} \mathrm{C}$, and then one volume $-20{ }^{\circ} \mathrm{C}$ of $96 \%$ ethanol was added while vortexing the samples. Cells could be stored at $4{ }^{\circ} \mathrm{C}$ until the analysis. In an experiment day cells were centrifuged (for 20 $\mathrm{min}$ in $2000 \mathrm{rpm}$ ), pelleted and re-suspended in staining solution contained $50 \mu \mathrm{g} / \mathrm{ml}$ of propidium iodide (PI) and $50 \mathrm{U} / \mathrm{ml}$ RNase A in PBS. Next samples were incubated at $37^{\circ} \mathrm{C}$ in the dark for $30 \mathrm{~min}$. Cells were analyzed using flow cytometry (LSRII from Becton Dickinson). Percentage of cells in each cell cycle phases were determined using FlowJo v10 software. Obtained results did not show statistically significant differences in cell cycle between compounds 12 and 16 treated and untreated

\section{Acknowledgements}

The project was generously supported by an internal grant from Wilkes University. We would like to thank Circa Group Pty. Ltd. Melbourne, Victoria, 3133, Australia, for a very generous gift of levoglucosenone. We thank Ms. Rachael Hohol for the measurements of optical rotation data for all compounds reported and Professor Peter Andreana and Ms. Kelly J. Lambright of University of Toledo for the help in the crystal structure analysis of $\mathbf{1 0}$. We thank Professor J. Dziadek and Professor T. Poplawski for collaborative efforts to determine biological activities.

\section{Supplementary Material}

The Supporting Information (X-ray analysis of compound $10^{23}$ and its ${ }^{1} \mathrm{H}$ and ${ }^{13} \mathrm{C}$ spectra) is available free of charge at: CCDC 12 Union Road, Cambridge CB2 1EZ, UK. ${ }^{23}$

\section{References and Notes}

1. Witczak, Z. J. ; Culhane, J. M. Appl. Microbiol Biotechnol. 2005, 69, 237. https://doi.org/10.1007/s00253-005-0156-x.

2. Witczak, Z. J. Curr. Med. Chem., 1999, 6, 165. https://doi.org/10189230

3. Robina, I.; Vogel,; P. ; Witczak, Z. J. Curr. Org. Chem., 2001, 15, 1177. https://doi.org/10.2174/1385272013374743

4. Witczak, Z. J. ; Chhabra, R. ; Chen, H. ; Xie, X-Q. Carbohydr.Res. 1997, 301, 167. https://doi.org/10.1016/S0008-6215(97)00100-6.

5. Witczak, Z. J. ; Kaplan. P.; Dey, P. M. Carbohydr. Res., 2003, 338, 11. https://doi.org/10.1016/S0008-6215(02)00394-4

6. Cagnoni, A. J.; Uhrig, M. L.; Varela, O. Bioorganic \& Med. Chem. 2009, 17, 6203. https://doi.org/10.1016/j.bmc.2009.07.055

7. Frayne, S. H. ; Murthy, R. R.; Northrop, B. H. J. Org Chem. 2017, 82, 7946. https://doi.org/10.1021/acs.joc.7b01200

8. Pachamuthu, K.; Schmidt, R. R. Chem. Rev. 2006, 106, 1, 160. https://doi.org/10.1021/cr040660c

9. Giri, G. F.; Danielli, M.; Marinelli, R. A.; Spanevello, R. A. Bioorg. Med Chem. Lett. 2016, 26, 3955. http://dx.doi.org/10.1016/i.bmcl.2016.07.007

10. Moya-Lopez, J. F.; Elhalem, E.; Recio, R.; Alvarez, E.; Fernandez, I.; Khiar, N. Org Biomol.Chem., 2015, 13, 1904. 
https://doi.org/10.1039/C4OB02030H

11. Ngoje, P.; Crich, D. J. Am. Chem. Soc. 2020, 142, 17, 7760.

https://doi.org/10.1021/jacs.0c03215

12. Mandhapati, A.R.; Rajender, S.; Shaw, J.: D. Crich, D, Angew. Chem. Int. Ed. Engl. 2015, 54, 1275. https://doi.org/10.1002/anie;

13. Dhakal, B.; Buda, S. Crich, D. J. Org. Chem. 2016, 81, 10617. https://doi.org/10.1021/acs.joc.6b02221

14. Wanka, L.; Iqbal, K.; Schreiner, P.R. Chem. Rev. 2013, 113, 3516. https://doi.org/10.1021/cr100264t

15. Korycka, M.; Machala, A. Brzostek, B. Dziadek, M. Kawka, T. Poplawski, Z. J. Witczak, J. Dziadek, Molecules, 2017, 22, 812.

https://doi.org/10.3390/molecules22050812

16. Korycka, M.; Machala, J. Pawelczyk, P. Borowka, B. Dziadek, A. Brzostek, M. Kawka, A. Bekier, S. Rykowski, A. Olejniczak, Strapagiel, D.; Witczak, Z. J. ; Dziadek, J. Cells, 2020, 9, 603. https://doi.org/10.3390/cells9030603

17. Khullar K.K.; Bauer L. J.Org.Chem., 1971, 36, 3038. https://doi.org/10.1021/jo00819a02916.

18. Ibatulin, F. M.; Shabalin, K. A.; Janis, J.V.; Shavva, A.G. Tetrahedron Lett. 2003, 44, 7961. https://doi:10.1016/j.tetlet.2003.08.120.

19. Ibatullin, F. M.; Shabalin, K. A.; Janis, J. V.; Selivanov, S. I. Tetrahedron Lett. 2001, 42, 4565. https://doi.org/10.1016/S0040-4039(01)00775-4.

20. Ibatullin, F. M.; S. I. Selivanov.; A.G. Shavva, Synthesis, 2001, 3, 419 https://doi.org/10.1055/s-2001-11443.

21. Domino and Rearrangement Reaction in Carbohydrate Chemistry: New Development and Strategies in Glycoscience; Witczak, Z. J.; Bielski, R. Eds.; John Wiley \& Sons, New York, 2016; pp. 10-19.

22. Czubatka-Bienkowska, A.; Sarnik, J.; Macieja, A.; Witczak, Z. J.; Poplawski, T. $252^{\text {th }}$ ACS National Meeting, Philadelphia, PA, August 20-24, 2016, Abstract \# MEDI- 0331

23. Crystallographic data for the structure $\mathbf{1 0}$ reported in this paper have been deposited with Cambridge Crystallographic Data Centre and allocated the deposition number CCDC Number: 2025096. Copies of the data can be obtained free of charge, on application to CCDC 12 Union Road, Cambridge CB2 1EZ, UK (fax $p$ 441223336033 or e-mail: de-posit@ccdc.com.ac.uk).

24 Clinical Laboratory Standards and Institute. Methods for Dilution Antimicrobial Susceptibility Tests for

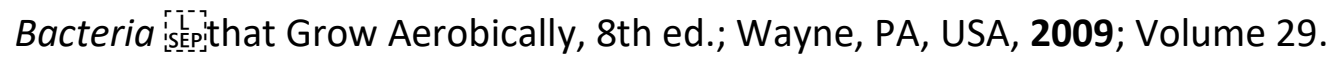

